\title{
Tuberculous Pleuro-Cutaneous Fistula
}

\author{
Jamal Ghalimi ${ }^{1}$, Sani Rabiou ${ }^{*}$, Marwane Lakranbi ${ }^{1}$, Nadia Anoun', Yassine Ouadnouni ${ }^{1,2}$, \\ Mohamed Smahi'1,2 \\ ${ }^{1}$ Department of Thoracic Surgery, Hassan II University Hospital, Fez, Morocco \\ ${ }^{2}$ Faculty of Medicine and Pharmacy, Sidi Mohamed Benabdellah University, Fez, Morocco \\ Email: ${ }^{*}$ rabiousani2@gmail.com
}

Received 5 April 2015; accepted 17 July 2015; published 20 July 2015

Copyright (C) 2015 by authors and Scientific Research Publishing Inc.

This work is licensed under the Creative Commons Attribution International License (CC BY).

http://creativecommons.org/licenses/by/4.0/

(c) (i) Open Access

\section{Abstract}

Introduction: The pleural fistulas are defined by a fistula communicating the pleural cavity to the chest wall. They often occur in the immunocompromised individuals with pyogenic infections, much more rarely in immunocompetent patients with tuberculosis. Materials and Methods: Between February 2010 and August 2012, five patients were followed up and operated for tuberculous pleuro-cutaneous fistula in the thoracic surgery department of University Hospital Hassan II of Fez. Results: These were 2 female and 3 male patients, with the average age of 39 years, and the age ranging from 18 years to 60 years. One patient was operated on for tuberculous empyema; there are 20 years and another 15 years ago drained for tuberculous empyema. All patients had a fistula necessitated operating on an average of three years, with extremes ranging from 15 days to 6 years. The radiological assessment had objectified chronic pleural pocket in one case, a costal osteitis in 2 cases, multiple cystic lesions in one case and apseudotumor appearance and endo exothoracique in another. Patients had benefited from draining the abscess with fistula resection associated with a rib resection in 2 cases and thoracostomy with lung prosthesis in one case. Conclusion: Tuberculous pleuro-cutaneous fistula is a rare pathological entity, occurring most often in an array of multifocal tuberculosis, or as a complication of surgery for tuberculous empyema.

\section{Keywords}

Pleuro-Cutaneous Fistula, Abscess, Tuberculosis, Chest Wall, Surgery

\section{Introduction}

Tuberculosis is a disease that affects all organs. The localization to the chest wall is very rare, in the order of $0.1 \%$ to $1 \%$ of all cases. The involvement of the intercostal spaces with or without bone localization revealed by

\footnotetext{
*Corresponding author.
} 
a subcutaneous abscess is much rarer. The complicated pleural fistulas are exceptional. Extra pulmonary tuberculosis represents $15 \%$ to $20 \%$ of the cases of tuberculosis; the thoracic localisation is scarcely found, representing $1 \%-5 \%$ of musculo skeletal involvement. It is the second most common cause of costal lytic lesions, the first being metastastic lesions [1].

The pleural fistulas often occur in immunocompromised individuals with pyogenic infections, rarely with unifocal or multifocal thoracic tuberculosis and exceptionally rarely with post surgical thoracic tuberculosis.

\section{Materials and Methods}

This is a retrospective study conducted between February 2010 and August 2012, 5 patients were monitored and operated for pleural skin fistula of tuberculous origin in the service of Thoracic Surgery Hassan II University Teaching Hospital of Fez. Demographic features (age, sex, including surgical history), clinical (chest swelling, fistula), biological (search for acid-fast bacilli in sputum and in histological samples, full blood count and Creactive protein-) were analyzed. The patients were investigated by anteroposterior and lateral chest radiographs, a chest CT scan with bone reconstruction $(n=5)$ and fistulogram $(n: 2)$. We were interested in the surgery performed (surgical approach, type of resection or plasty), and followed thereafter by the descriptive analysis of the data set.

\section{Results}

These 5 patients ( 2 female and 3 male), aged between 18 to 60 years, all of low socio-economic status. Two patients had been treated for tuberculous empyema (one was operated 20 years ago, who underwent pleuropulmonary decortication, another one the tuberculous empyema was drained 15 years ago) and another patient was operated several times for swelling of chest wall during the last six years without bacteriological or histological documents.

The onset of the disease was insidious in 4 patients (an average of 3 years), marked by the finding of chest wall swelling with progressive worsening from pus after several months of development (Figure 1). Fever was present in all cases. Among the cases on had l multiple swellings unlike the other cases. No concomitant sign of active tuberculosis was noted. Laboratory findings, showed nothing in particular except a slight elevation of C-reactive protein, in all patients and leukocytosis reaching to 22,000 cells $/ \mathrm{mm}$ in one case. Chest ultrasound was performed in two cases, it showed a tissue mass with heterogeneous tumor appearance.

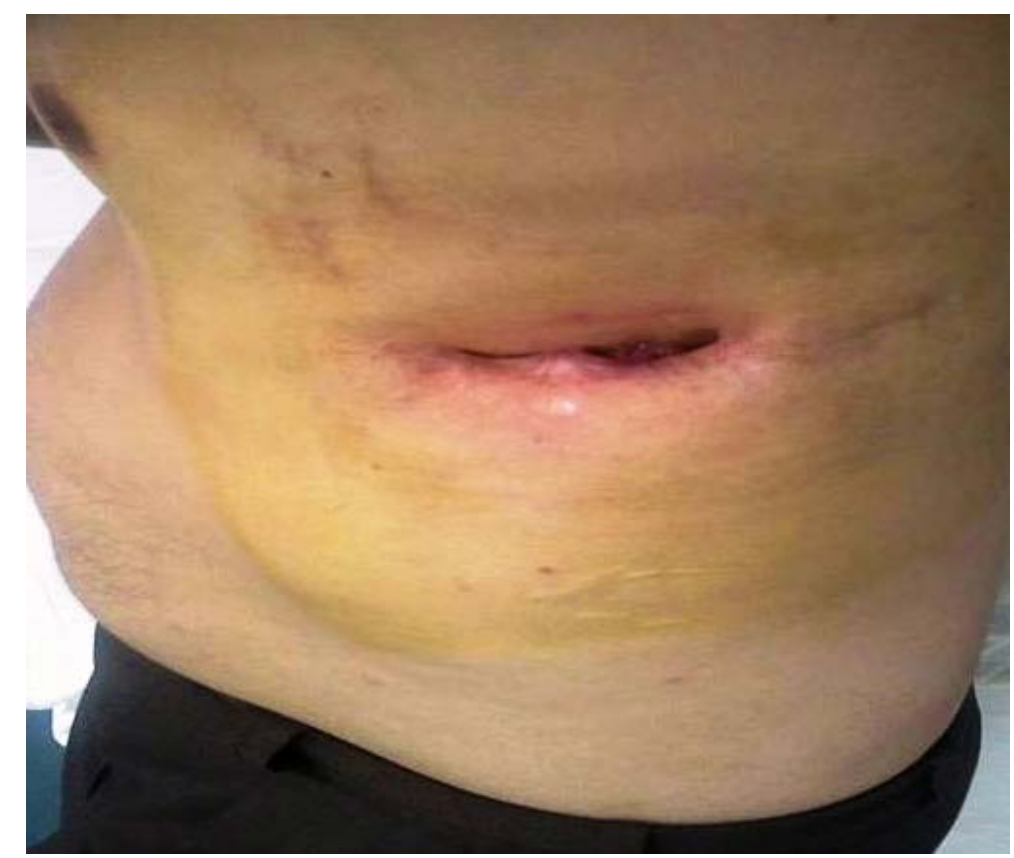

Figure 1. Pleuro-cutaneous fistula in the anterior portion of the old thoracotomy. 
Thoracic computed tomography performed in all patients, supplemented by fistulogram in two of them, has shown in one case after chronic pleural pocket which fistulized skin with pachy-pleuritis (Figure 2), lytic rib images in wide communication between the skin and the pleural space as in all cases, multiple cystic lesions (paravertebral, cervical and pleural) in a case (Figure 3) and a pseudo-tumor appearance endothoracic in one and exothoracic in another.

Diagnostic confirmation was essentially histological. The presence of Acid and alcohol fast bacilli on direct microscopy examination or culture of the pus was never found in any case, despite repeated samples before surgery (average of 3 samples). Histological examination of the surgical specimen showed in all cases a fibrinous seat of epithelioid granulomas and giant cells associated with caseous necrosis in one case.

Patients had benefited from draining of the abscess with sinus tract resection associated with a rib resection in two cases and a thoracostomy with lung prosthesis given the impossibility of a second pleuropulmonary decortication in a case (Figure 4). The immediate postoperative course was uneventful in all cases with a postopera-

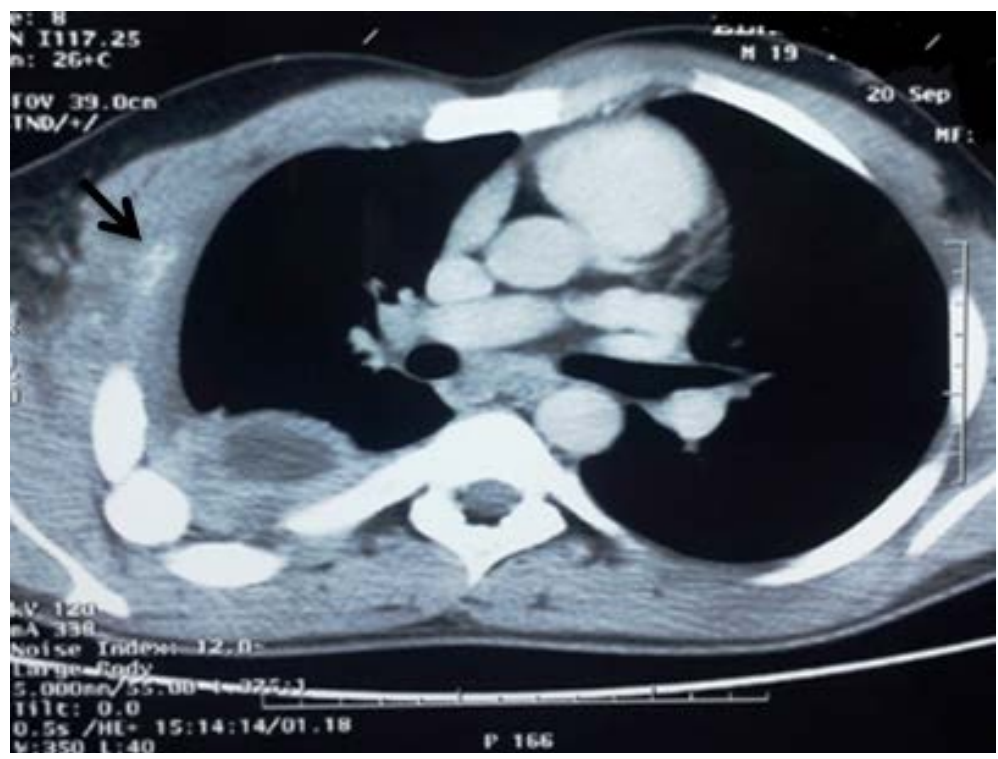

Figure 2. CT scan showing: pleural back pocket with pachy-costal pleurisy and costal lysis (arrow).

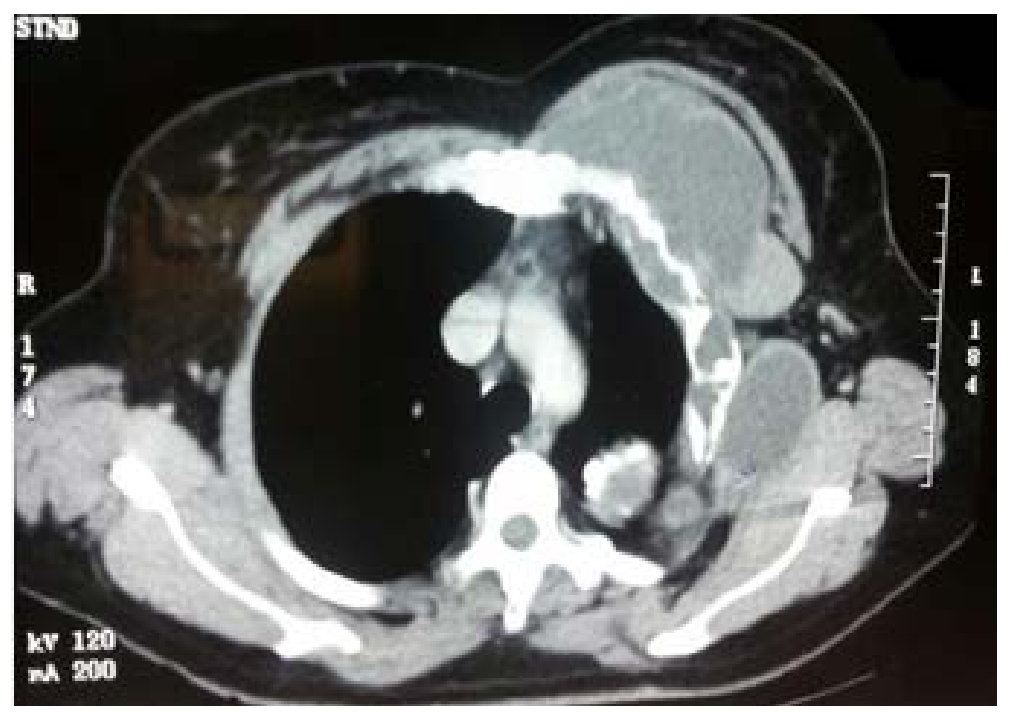

Figure 3. CT scan showing: liquid mass endo and exo thoracic with costal lysis and extension to soft tissues. 
tive hospital stay which did not exceed 12 days. Additional medical treatment was instituted, it was antituberculous drugs with the doses and durations as recommended by the WHO. After a mean follow up of 12 months, one patient was prepared for myoplasty. All others remain asymptomatic and have returned to normal physical and occupational activity. Clinical information of the 5 patients are presented in Table 1.

\section{Discussion}

Tuberculosis of the chest wall can reach all anatomical structures. The intercostal space location with or without bone involvement revealed by a subcutaneous abscess, however is rare, and well known throughout the literature [1]. The fistulizing form of communication between the pleura to the skin is not reported. These forms are observed when met with certain risk factors, such as the difficulties of etiological diagnosis, the longer period of

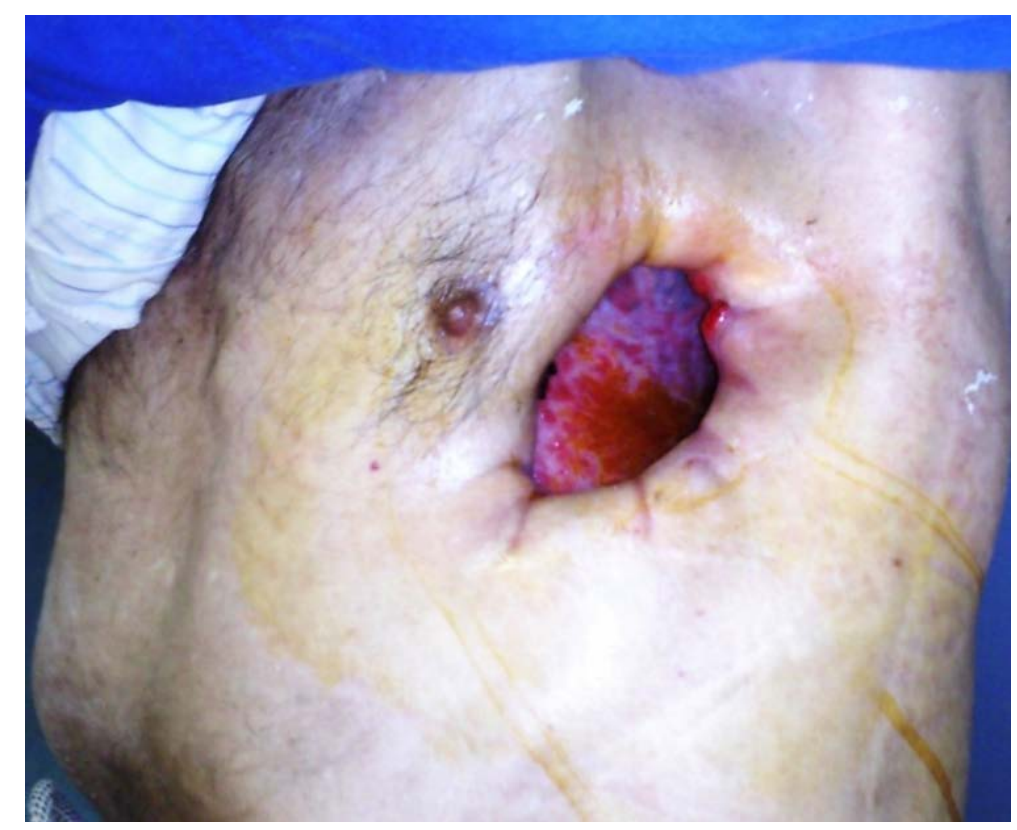

Figure 4. Thoracostomy with underlying lung prosthetics.

Table 1. Clinical information of the 5 patients.

\begin{tabular}{|c|c|c|c|c|c|}
\hline Patient & Sex/Age & Clinic & Imagery & Treatment & Evolution \\
\hline 1 & Women/60 years & $\begin{array}{l}\text { Left under mammary } \\
\text { tumefaction since } 4 \\
\text { months fistulized in the skin }\end{array}$ & $\begin{array}{c}\text { Fistulized parietal } \\
\text { Collection with costal } \\
\text { lysis }\end{array}$ & $\begin{array}{l}\text { Flattening of the fistulous } \\
\text { journey with resection } \\
\text { chondrocostal }\end{array}$ & $\begin{array}{l}\text { Good evolution under } \\
\text { anti bacillary }\end{array}$ \\
\hline 2 & Men/19 years & $\begin{array}{l}\text { - Drained since } 4 \text { years } \\
\text { tuberculous pyothorax } \\
\text { - Persistence of a fistula at the } \\
\text { level of the drain hole }\end{array}$ & $\begin{array}{l}\text { Chronic posterior pleural } \\
\text { Pocket fistulized to the } \\
\text { skin with broadcasts } \\
\text { pachypleurite }\end{array}$ & $\begin{array}{l}\text { Setting flat of the pleural } \\
\text { pocket and fistulous route } \\
\text { with pulmonary decortication }\end{array}$ & $\begin{array}{l}\text { Good evolution under } \\
\text { anti bacillary }\end{array}$ \\
\hline 3 & Women/42 years & $\begin{array}{l}\text { - Operated several times for } \\
\text { chest wall masses } \\
\text { - Diffuse cystic lesion in the } \\
\text { anterior thoracic wall }\end{array}$ & $\begin{array}{l}\text { Parietal cystic lesions, } \\
\text { associated to bone lysis } \\
\text { (side and dorsal spine). }\end{array}$ & $\begin{array}{c}\text { Flattening the greatest mass } \\
\text { that proved intraoperatively } \\
\text { fistulized in endothoracic }\end{array}$ & $\begin{array}{l}\text { Good evolution under } \\
\text { anti bacillary }\end{array}$ \\
\hline 4 & Men/46 years & $\begin{array}{c}\text { - Operated since } 20 \text { years for lef } \\
\text { pyothorax } \\
\text { - Persistence of } \\
\text { pleuro-cutaneous fistula }\end{array}$ & $\begin{array}{l}\text { Multiple osteitis fistulized } \\
\text { skin, communicating with } \\
\text { the pleural space under } \\
\text { Thick pacchypleurite }\end{array}$ & $\begin{array}{l}\text { Flattening of the fistulous } \\
\text { journey, resection of the } \\
\text { sides then thoracostomy }\end{array}$ & $\begin{array}{l}\text { Good evolution under } \\
\text { anti bacillary with } \\
\text { filling of the } \\
\text { thoracostomy }\end{array}$ \\
\hline 5 & Men/18 years & $\begin{array}{l}\text { Right anterior swelling chest } \\
\text { with a small right fistulized } \\
\text { axillary }\end{array}$ & $\begin{array}{l}\text { Large collection } \\
\text { of chest wall }\end{array}$ & $\begin{array}{l}\text { Flattening of the abscess } \\
\text { with resection of the } \\
\text { fistulous journey }\end{array}$ & $\begin{array}{l}\text { Good evolution under } \\
\text { anti bacillary }\end{array}$ \\
\hline
\end{tabular}


taking appropriate therapeutic management due to nonspecific prior antibiotic therapy, immunocompromised patients [1] [2].

The pathogenesis of tuberculosis of the chest wall is multiple. Certainly, the large medullary activity ribs and sternum provides suitable conditions for the local development of acid-fast bacilli; however, the mechanisms of contamination are still discussed: extension by contiguity of pulmonary or pleural disease, hematogenous spread, direct inoculation through transcutaneous extension from lymphadenitis of the chest wall [2] [3].

Fistulisation of both the skin and the pleural cavity is poorly described, unlike during pyogenic empyema, the mechanism is not clear, most often secondary to tuberculous adenitis with intrathoracic extension. The occurrence of this post surgical tuberculosis fistula or in the aftermath of pleural drainage for tuberculous empyema is exceptional, however, and is fraught with consequences [2]-[5].

Pleural skin fistula of tuberculous origin is observed in both sexes and at any age, but most often in adolescents and young adults. In our series, four patients, $80 \%$ were under 40 years with a sex ratio estimated at 1.5.

Clinically, the onset is insidious marked by a soft swelling with pus coming through a fistula. There may be low grade fever or no fever at all. These fistulated abscesses sit electively in the latero-sternal region made by the preferential involvement of the intercostal lymphnodes earlier.

Radiologically: conventional radiography has little role especially in the early stages. In advanced stages, the images may falsely suggest a malignant tumor, especially if there is osteolytic lesions. The fistulogram, meanwhile, remains a great diagnostic and therapeutic contribution to the tracking of the sinus tract to its origin, especially as the color of the fistula by methylene blue helps the surgeon in the dissection and surgical excision of infected tissue [6].

The thoracic scan is essential for the assessment of the lesions, including search for subclinical bone disease that perpetuates the infection, despite TB treatment and helps with surgical approach [7] [8].

The etiologic diagnosis of the fistula remains equally difficult than in non fistulized abscess may then wander to the pyogenic abscess or malignant tumor process. The demonstration of acid-fast bacilli resistant to direct examination and/or culture is often disappointing. In our experience, it is the pathological examination which gave us quick and satisfactory results and allowed us to start early specific treatment of tuberculosis [1]-[3] [9].

At the stage of fistula with bone lesions localized, surgical treatment is required, the need for the flat sinus tract with discharge or even resection of the abscess in full and all necrotic tissue is the only guarantee to achieve healing [9]-[11]. In addition to surgery, treatment with antituberculous drugs is needed as recommended by WHO, especially in highly endemic areas where relapses are described, partly due to a lack of compliance.

\section{Conclusion}

Pleuro-cutaneous fistula of tuberculous origin is a rare pathological entity of which various clinical and radiological aspects can sometimes be misled. However, there is usually excellent prognosis with correct treatment, hence the need to make every effort to ensure early diagnosis. Management is usually surgical and medical with antituberculous drugs.

\section{Conflict of Interest}

The authors had no conflict of interest to declare.

\section{References}

[1] Pertuiset, E. (2004) Tuberculose osseuse et articulaire des membres. EMC-Rhumatologie Orthopédie, 1, 463-486. http://dx.doi.org/10.1016/j.emcrho.2004.08.003

[2] Ka, A.S., Brousse, V., Diakhaté, I., et al. (2006) Abcès froid tuberculeux de la paroi thoracique chez l'enfant: A propos de 3 cas. Archives de Pédiatrie, 13, 1265-1266. http://dx.doi.org/10.1016/j.arcped.2006.06.009

[3] Bouslama, K., Bakir, L., Ben M’Rad, S., et al. (1998) Tuberculose de la paroi thoracique: A propos d'un cas et revue de la littérature. Médecine et Maladies Infectieuses, 28, 666-667. http://dx.doi.org/10.1016/S0399-077X(98)80042-5

[4] Prasoon, D. (2003) Tuberculosis of the Intercostal Lymph Nodes. Acta Cytologica, 47, 51-55. http://dx.doi.org/10.1159/000326475

[5] Navani, N., Punwani, S., Humphries, P.D., et al. (2010) Pleuro-Cutaneous Fistula Complicating Chest Drain Insertion for Tuberculous Effusion. QJM, 103, 799-800. http://dx.doi.org/10.1093/qjmed/hcp175 
[6] Chermiti Ben-Abdallah, F., Boudaya, M.S., Chtourou, A., et al. (2013) Tuberculose sternale avec fracture spontanee du sternum. Revue de Pneumologie Clinique, 69, 89-92. http://dx.doi.org/10.1016/j.pneumo.2013.01.003

[7] Morris, B.S., Maheshwari, M. and Chalwa, A. (2004) Chest Wall Tuberculosis: A Review of CT Appearances. British Journal of Radiology, 77, 449-457. http://dx.doi.org/10.1259/bjr/82634045

[8] Shah, J., Patkar, D., Parikh, B., et al. (2000) Tuberculosis of the Sternum and Clavicle: Imaging Findings in 15 Patients. Skeletal Radiology, 29, 447-453. http://dx.doi.org/10.1007/s002560000207

[9] Chang, J.H., Kim, S.K. and Lee, W.Y. (1999) Diagnostic Issues in Tuberculosis of the Ribs with a Review of 12 Surgically Proven Cases. Respirology, 4, 249-253. http://dx.doi.org/10.1046/j.1440-1843.1999.00183.x

[10] Paik, H.C., Chung, K.Y. and Kang, J.H. (2002) Surgical Treatment of Tuberculous Cold Abscess of the Chest Wall. Yonsei Medical Journal, 43, 309-314. http://dx.doi.org/10.3349/ymj.2002.43.3.309

[11] Lim, S.Y., Pyon, J.K., Mun G.H., et al. (2010) Reconstructive Surgical Treatment of Tuberculosis Abscess in the Chest Wall. Annals of Plastic Surgery, 64, 302-306. http://dx.doi.org/10.1097/SAP.0b013e3181b0bb03 